\title{
SABORES Y SABERES: PERSPECTIVAS PEDAGÓGICAS DE LA PLAZA DE MERCADO DEL SUR DE TUNJA (COLOMBIA) $)^{(*)}$
}

Ángela Jasmín Fonseca Reyes ${ }^{(*)}$

En la plaza de mercado del sur de $\operatorname{Tunja}^{1}$ se comercializan diversos productos, especialmente frutas, verduras, artesanías y ganado. Como su nombre lo indica, está ubicada en el sur de la ciudad, arraigada a las veredas y a los municipios aledaños, y por lo mismo, apartada del acelerado crecimiento de la urbe que se ha transformado epicentro de grandes construcciones, cambiando su semblante de "villa" a ciudad abierta y comercial.

Desde las primeras horas de la mañana mucho antes de que el sol aparezca en el horizonte, la plaza de mercado del sur de Tunja despierta. Cientos de comerciantes concurren al lugar para adecuar el espacio y organizar la mercancía que será vendida durante la jornada. Respectivamente, cientos de compradores se ponen cita en el lugar para adquirir los más variados y frescos productos al menor precio en la ciudad.

La plaza está dividida en pabellones y secciones que en un día de mercado y a simple vista son difíciles de diferenciar, ya que muchos puestos se encuentran ubicados a la intemperie, sin una estructura definida. A pesar de esto, los colores, los olores y los sabores que se generan en cada espacio son particulares.

Este es un escenario volátil que no se encuentra totalmente confinado a los límites de las rejas y portones colocados en la extensión del predio dispuesto para su funcionamiento. Se encuentra en constante movimiento, dentro y fuera del recinto. En un andar constante, entre gritos, carretas y puestos improvisados en los andenes e incluso calles aledañas, su orden se opone a las normas de la ciudad limpia y sistematizada.

Diversas personas acuden al lugar en día de mercado: trabajadores y desempleados, campesinos y citadinos, nativos y extranjeros, jóvenes y viejos, los del norte y sobre todo los del

\footnotetext{
${ }^{(*)}$ Este trabalho é resultado da pesquisa: Da barraca ao escritório: perspectivas pedagógicas da feira livre do sul de Tunja (Colômbia), realizada como requisito para obter o título de mestra em educação pela Universidade Federal Fluminense.

${ }^{(*)}$ Mestra em educação pela Universidade Federal Fluminense (UFF). Licenciada em ciências sociais pela Universidad Pedagógica y Tecnológica de Colombia (UPTC). E-mial: angelafonrey@gmail.com.

1 Tunja es una ciudad andina con una extensión de $121,5 \mathrm{~km}^{2}$, ubicada a $130 \mathrm{Km}$ de Bogotá. Es la capital del departamento de Boyacá. Se encuentra en la región Centro Oriente de Colombia.
} 
sur, quienes aprovechan los bajos precios que ofrecen los vendedores, se mezclan entre la multitud en la frenética danza de la plaza.

Las plazas de mercado son lugares de memoria, de encuentro y de socialización cuya relevancia física y simbólica está ligada a las dinámicas de ocupación y uso del espacio por parte de las comunidades. Archela afirma que, "como parte do espaço, o lugar é ocupado por sociedades que ali habitam e estabelecem laços tanto no âmbito afetivo, como também nas relações de sobrevivência. (...) O lugar é o espaço que se torna familiar às pessoas, consiste no espaço vivido da experiência" (2004, p. 129).

Es un universo donde se mezclan lo colorido y lo sombrío, es un encuentro retumbante, que estimula a oír con los ojos y ver con los oídos en una sinestesia espacial, puesto que "olhos e ouvidos não devem ser entendidos como teclados separados para o registro de sensações, mas, sim, como órgãos do corpo como um todo em cujo movimento, dentro do ambiente, consiste a atividade de percepção" (INGOLD, 2008, p. 29).

Figura 1. La plaza desde afuera.

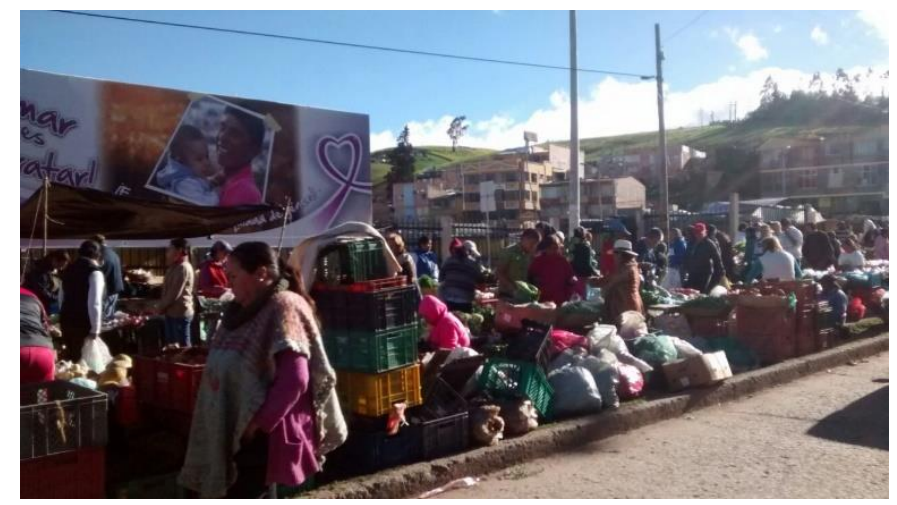

Fuente: Archivo personal (agosto de 2017)

La plaza se oye, se huele, se saborea y se siente en cada palabra y en cada rostro, en las manos que hábilmente desgranan y cocinan, en las sonrisas, en los consejos, en las historias, en los chistes que dinamizan la jornada, en los saludos y promociones, en los descuentos, en los encimes, incluso en los malentendidos y disgustos. Es decir, la plaza está en la gente, tiene nombre e identidad.

El sentido de la plaza se encuentra en las personas que la frecuentan, el lugar como tal, desolado y en silencio no representa más que un conjunto de estancias viejas y deterioradas. En cambio, en movimiento, la plaza es un recinto en donde los bienes y prácticas cotidianas dan cuenta de los habitus de los agentes, que según Bourdieu son "sujetos actuantes y conscientes" que cuentan con un sentido práctico de la realidad (1997, p. 116). 
De igual forma, allí se reúnen y mezclan acentos, idiomas, nacionalidades, historias y saberes que hacen de ella un local educativo a cielo abierto. Por esto, es un lugar antropológico donde circulan diversos conocimientos, que se encuentran en constante transmisión, modificación o reafirmación:

Reservamos el término "lugar antropológico" para esta construcción concreta y simbólica del espacio que no podría por sí sola dar cuenta de las vicisitudes y de las contradicciones de la vida social pero a la cual se refieren todos aquellos a quienes ella les asigna un lugar, por modesto o humilde que sea. Justamente porque toda antropología es antropología de la antropología de los otros, en otros términos, que el lugar, el lugar antropológico, es al mismo tiempo principio de sentido para aquellos que lo habitan y principio de inteligibilidad para aquel que lo observa. (AUGÉ, 1992, p. 30).

Las relaciones comerciales dependen de la interacción y la comunicación, que usualmente sobrepasa las fronteras de la formalidad, generando un ambiente de familiaridad y proximidad, con valores simbólicos y de identificación

En este sentido, consideramos pertinente preguntarnos ¿cómo circulan los saberes y prácticas que persisten al interior de la plaza de mercado del sur? además ¿cuál es la funcionalidad y legitimidad de estos saberes dentro y fuera del contexto de la plaza?

Para dar respuesta a las cuestiones enunciadas, realizamos un trabajo de campo etnográfico, que vinculó observación participante y entrevistas con algunos comerciantes y trabajadores de la plaza. Esto nos permitió contemplar las dinámicas sociales que se producen en este lugar. Por esto, a lo largo del texto se tendrán en cuenta algunos fragmentos de las entrevistas realizadas con dos mujeres comerciantes, que trabajan en la plaza de mercado, quienes nos compartieron sus saberes sobre plantas medicinales, recetas y platos tradicionales.

\section{CAMINANDO LA PLAZA}

La permanencia de la plaza de mercado del sur, como lugar de ventas informales, contrasta con las nuevas formas de comercialización adoptadas en la ciudad tras la propagación de grandes almacenes y supermercados cuya organización espacial está diseñada para la rápida circulación de las personas y mercancías, estos no lugares (AUGÉ, 1992) potencian el menor contacto posible entre vendedores y compradores. 
Con el simple hecho de existir, la plaza, se opone al orden impecable de los confortables centros comerciales, supermercados y tiendas de cadena, ubicados en locales más asequibles y con condiciones físicas más llamativas. Sería ridículo pensar en que alguien, que frecuente estos lugares, pretenda negociar el valor final de algún producto, obtener encimes por la compra o pedir una prueba del producto para confirmar su calidad.

En cambio, la plaza descomplicada e informal invita a un constante contacto físico, visual, incluso emocional. Allí no se puede comprar sin antes conversar con el vendedor, que además de productos ofrece historias, cuentos y promociones. En palabras de Barbero "La plaza de mercado [es] para las masas populares un espacio fundamental de actividad, de producción de discurso propio, de prácticas en las que estalla un cierto imaginario -el mercantil- y la memoria popular se hace sujeto constituido desde otro imaginario y otra lengua" (1981, p. 3).

El pintoresco escenario ofrecido por la plaza, se configura como un espacio de sociabilidad y diálogo, en el cual también se comparten sabores y saberes, pues, las frutas y verduras adquiridas en cualquier puesto, vienen acompañadas de narraciones, consejos, plegarias y deseos, que le otorgan un valor simbólico al ejercicio de hacer mercado. "Estas maneras de hacer constituyen las mil prácticas a través de las cuales los usuarios se reapropian del espacio organizado por los técnicos de la producción sociocultural” (CERTEAU,2000. p. 16).

Figura 2. Fruta.

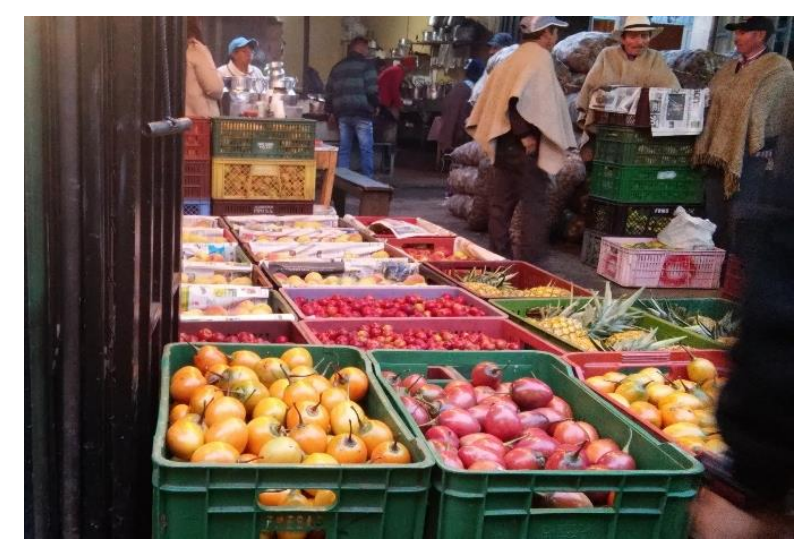

Fuente: Archivo personal (mayo de 2017)

Igualmente es espacio de reunión popular en donde se producen prácticas cotidianas de socialización que contribuyen a dinamizar los intercambios materiales y simbólicos. En su ensayo sobre el don, Mauss (1974) argumenta que los intercambios comerciales transcienden de su connotación económica y material a un espectro simbólico cuando se tornan dones o presentes, puesto que crean y fortalecen relaciones sociales entre los sujetos. 
En la plaza el valor simbólico de los intercambios se hace real en fenómenos como el encime o la ñapa, que alimentan y enriquecen las relaciones sociales, puesto que además de generar un intercambio de bienes materiales se otorga una parte de su alma, en cada saludo, frase afectuosa, consejo o deseo. Es decir, "No fundo são misturas. Misturam-se as vidas, e é assim que as pessoas e as coisas misturadas saem cada qual da sua esfera e se misturam: o que é precisamente o contrato da troca” (MAUSS, 1974, p. 71).

Estos intercambios también cuentan con una connotación educativa que se consolida a través de la creación, recreación y la transición de saberes que se materializan en recetas, remedios, preparaciones y demás usos de los frutos y plantas que se comercializan en la plaza. Por ello, esta evoca memorias que nos reconcilian momentáneamente con la herencia campesina que a muchos avergüenza, nos recuerda el origen de los alimentos en su estado natural, fuera de empaques y marcas.

\section{LA PLAZA: UN ESPACIO SOCIOEDUCATIVO}

Los saberes que se construyen en la plaza son tan diversos como la variedad de productos que aún son comercializados en este lugar, que nos liberan de otros consumos, por ejemplo, las platas medicinales frente a la medicina occidental, la comida tradicional en contraposición a la

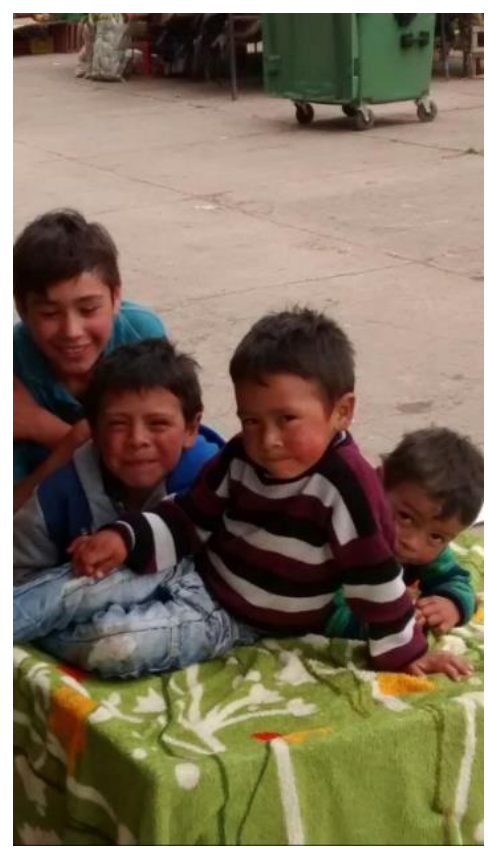

Figura 3. Los niños. Foto: archivo personal octubre de 2017. comida procesada con colorantes, conservantes, entre otros.

Este lugar se constituye como una opción laboral para un porcentaje importante de familias de las clases más populares de Tunja y municipios aledaños, que buscan una fuente de ingresos constante que no les exija estudios formales de educación o experiencia laboral certificada. Las relaciones laborales que se dan en la plaza son informales, porque no se encuentran mediadas por contratos, sino por pactos orales, que en este contexto cuentan con la misma o incluso mayor validez que los documentos escritos.

Formalmente, cada puesto está a nombre de un individuo, pero detrás de la organización del mismo se encuentra el trabajo conjunto de varios integrantes de una o más familias de diversas edades, desde niños hasta ancianos, que se encargan de realizar las diferentes actividades que demanda la plaza. La mayoría de 
comerciantes son mujeres cabeza de hogar. De estas, una cantidad significativa opta por llevar a sus hijos con ellas a la plaza.

En este contexto, al igual que en el campo, persiste la noción de que los niños deben relacionarse con las actividades que sus padres realizan, para que comprendan cómo funciona el campo o, en este caso, el puesto de la plaza. Los niños y adolescentes forman parte del núcleo familiar, por tanto, su presencia en el puesto es tan necesaria como la de cualquier otro miembro de la familia. El trabajo de la plaza es colectivo, así que, de la misma manera en que sus familiares adultos se encargan de múltiples actividades, los jóvenes también "colaboran" para equilibrar las cargas de trabajo.

En otras palabras, todos los miembros de la familia juegan un rol en la plaza, que se va ajustando de acuerdo con su edad, las destrezas que haya adquirido en determinadas tareas y a las necesidades del puesto. La "colaboración” de los hijos en la plaza cuenta con una connotación simbólica y no económica, porque las relaciones familiares anulan las laborales.

La Plaza es un espacio unificador e intermediario entre el mundo privado correspondiente a la casa y el público ligado a la calle (DA MATTA, 1997, p. 93), pues en ella coexisten formas de ser y hacer que ultrapasan los límites impuestos para cada universo.

Por otro lado, las dinámicas de sociabilidad que se generan entre compradores y vendedores se dan en un ambiente de familiaridad, puesto que se crean relaciones de intercambio comercial, se mantienen conversaciones, se comparten experiencias y anécdotas, además de consejos en torno a la alimentación, la cocina y la salud. "Estas formas simples no caracterizan los grandes espacios políticos o económicos, sino que definen al mismo tiempo el espacio aldeano y el espacio doméstico" (AUGÉ, 1992, p. 33).

Las ventas, el trabajo y desorden relacionados estrictamente con la esfera pública, es decir, con la calle, se mezclan con los quehaceres de limpieza, apropiación y organización de los alimentos y los puestos de mercado; actividades privadas que nos remiten al hogar. Las fronteras impuestas entre ambos mundos se desdibujan en el cotidiano de la plaza, las diferentes tareas que demanda mantener uno o varios puestos, exigen la intervención de más de una persona.

El sistema de valores que se cohesionan en este ambiente reafirman la estructura de jerarquía imperante en el hogar, puesto que las tareas asignadas a cada miembro se dan de acuerdo con su edad y su género. Habitualmente los hombres se encargan de las actividades que requieren mayor esfuerzo físico, como cargar y descargar la mercancía; las mujeres deben suplir las tareas 
restantes, o sea adecuar el puesto, arreglar, organizar y exponer los productos de acuerdo al orden que consideren pertinente, limpiar el lugar, etc., además de encargarse del cuidado de los hijos.

La presencia de los niños en la plaza no condiciona el interés de sus padres en que estos estudien, por el contrario, los comerciantes consideran indispensable que estos hagan parte del sistema educativo formal, pues asumen que la escuela va a permitir que sus hijos en el futuro tengan mayores oportunidades y un horizonte laboral más amplio.

La Organización Internacional del Trabajo (OIT) reconoce que la participación de los niños y adolescentes en tareas domésticas o comerciales no necesariamente debe clasificarse como trabajo infantil que deba erradicarse pues "este tipo de actividades son provechosas para el desarrollo de los pequeños y el bienestar de la familia; les proporcionan calificaciones y experiencia, y les ayuda a prepararse para ser miembros productivos de la sociedad en la edad adulta" (OIT, 2017).

No obstante, esta mirada no abarca el valor de la participación de los niños en las actividades de la plaza porque allí el trabajo es informal y en muchas circunstancias es más simbólico que material. En la plaza, los niños, las niñas y los jóvenes aprenden a desenvolverse en un contexto que les exige entrar en contacto con más personas, establecer relaciones, socializar, comprender las dinámicas de venta y compra de productos prácticas que permiten saber sobre los frutos de la tierra, su producción y comercialización. Así se aprende y enseña haciendo, narrando, oyendo, interactuando, etc.

El trabajo de la plaza requiere dedicación, constancia, agilidad y destreza: habilidades que se aprenden con la práctica. Además, la interacción con el espacio sensorial y con personas de diferentes procedencias, edades y ocupaciones permite construir experiencias sociales. En otras palabras, en la plaza los niños y jóvenes aprenden a ser parte de la sociedad, porque se relacionan con los patrones sociales de conducta de los individuos que los rodean (BERGER; BERGER, 1977).

En este sentido, los padres depositan confianza en las habilidades que el niño o la niña va adquiriendo mediante la práctica de ciertas tareas, de esta forma para él o ella resulta más fácil actuar con autonomía y tomar decisiones. En la medida en que estos se relacionan con el cotidiano de la plaza y empiezan a adquirir responsabilidades, sus percepciones sobre el contexto se transforman. Freire argumenta que

O homem enche de cultura os espaços geográficos e históricos. Cultura é tudo o que é criado pelo homem. Desde uma poesia como uma frase de saudação. A cultura 
consiste em recriar e não em repetir. O homem pode fazê-lo porque tem uma consciência capaz de captar o mundo e transforma-lo (2014, p. 38).

Por el constante contacto con los diversos frutos que llegan a la plaza, se adquieren habilidades para reconocer los niveles de maduración y la calidad de los productos que serán comercializados, pues de esto depende el éxito de sus ventas y la permanencia de su clientela. Pequeños detalles como el olor, el color, la textura evidencian las condiciones de los frutos y su grado de maduración. Doña Cecilia, además de promocionar su mercancía, nos enseñó a escoger aguacates:

- Le tengo aguacates mi veci, fresquitos. Para lo que desee, así bien maduritos como para ensalada o para ahorita el almuerzo. Este le amanece listo para comer mañana, este si le toca hoy porque ya está madurito y este le queda para el domingo, hasta el lunes le alcanza a durar, sin que se le dañe.

El buen aguacate muchas veces depende es de donde uno lo compra. Yo tengo un buen proveedor, por eso aquí fijo hay aguacate bueno. Mírelo bien, este que ya está listo no huele igual que este que se demora más en quedar maduro. Aquí en la puntica, si le ve el color. Ese verde es de maduro, el tono lo va tomando de un día para otro, por eso le toca a uno saber cuál es que está listo primero. Eso no es solo cogerlo y sentirlo blandito. Porque puede que esté blandito pero que no haya madurado bien, que esté magullado. Y si está magullado o negrito no es el problema, el problema es pensar en qué prepararlo para que no se dañe. Entonces estos que están casi pasaditos son los propios para guacamole o ají. Los otros si se pueden comer así.

El reconocimiento de estos detalles es aprendido mediante la observación y constante contacto con los productos. Dependiendo de las condiciones de los frutos a comercializar, es decir verdes o maduros, generalmente habrá una recomendación sobre cómo prepararlos para aprovecharlos al máximo. Además de las menciones las múltiples virtudes nutricionales o curativas que poseen las frutas o las verduras.

Para los compradores, el hecho de que los comerciantes sepan este tipo de detalles representa confiabilidad y certeza de que los productos que están comprando llenarán sus expectativas. De igual forma, muchos compradores acuden a la plaza en busca de remedios naturales y consejos para mejorar su salud. 
Figura 4. Hierbas aromáticas.

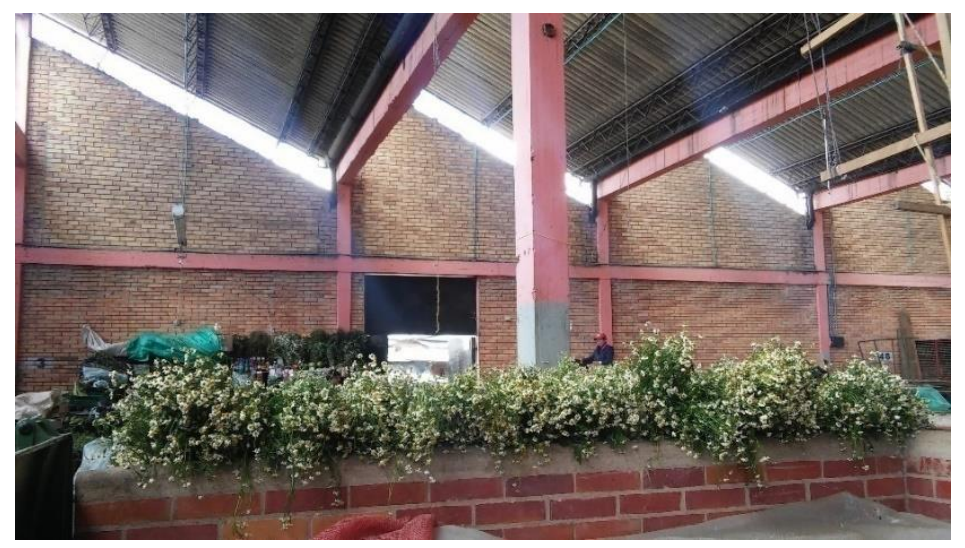

Foto: Archivo personal.

Amanda, tiene 21 años los mismos que su mamá lleva trabajando en la plaza vendiendo hierbas. Durante sus años de colegio siempre se mantuvo distanciada de la plaza. Sin embargo, no ha logrado continuar una carrera universitaria por la carencia de opciones laborales, ya que quiere pagársela ella misma, por ello resolvió trabajar en el puesto de su mamá desde hace cuatro años.

A pesar de que debe realizar las mismas tareas, cada día trae experiencias nuevas, puesto que esta labor la ha aproximado a otros saberes, que distan enormemente de los institucionalizados en la escuela.

- Aquí yo aprendí a relacionarme, a hablar con la gente, porque antes yo era muy tímida, ahora me resulta fácil entrarle a la gente, ofrecerle las hierbas y también hacer amigos. Antes yo no me aguantaba que me dijeran nada, me ponía brava, mejor dicho. Aquí quiera o no tengo que hablar con las personas, entonces desde que me traten decentemente, yo también soy de tratar, hasta les hago chistes y me burlo con los que ya tengo confianza.

[...]Yo a ti te puedo ofrecer toda clase de plantas que son buenas para tu salud, para hacer tratamientos de belleza, para el pelo, la cara, para adelgazar. Y eso me lo enseñó la plaza, aquí entre las hierbas y hablando con la gente.

[...]Cuando yo comencé no tenía la menor idea de para qué era cada hierba, me preguntaban y cuando no sabía decía que no había o me inventaba algo, y la misma gente me decía, "como que no hay si desde aquí la estoy viendo" y yo decía ay es que estoy mal de la vista (risas) pero por eso mismo me vi obligada a consultar, a preguntar. Y con mi mamá y las demás personas que trabajan aquí fue que empecé a interesarme, porque antes para mí todo esto era el mismo pasto, pero ya ves que todas son muy diferentes. 
De acuerdo con De Vargas (2009) el saber hacer sólo es aprehendido mediante la práctica y es reproducido en las relaciones sociales, lo que genera a la vez una valorización y ejercicio de las tradiciones en constante reinvención. Aprender es una experiencia social y en comunidades como la plaza se encuentra situada y potenciada desde la práctica, lo que contribuye a que el conocimiento se diversifique y trasforme, pues cada individuo imprime en su experiencia formas particulares de ser y hacer determinada actividad técnica.

\section{OTROS MUNDOS, OTROS SABERES}

La plaza deja de ser un lugar exclusivamente de intercambio comercial para configurarse como un lugar educativo, puesto que las prácticas y saberes que se mantienen vigentes y su cotidianidad no se encuentran objetivados dentro de los criterios universalistas de la ciencia moderna occidental, ni homogenizados dentro de la lógica neoliberal (SANTOS, 2007, p. 143).

Lave (2015) argumenta que, existe una relación dialéctica entre la producción de aprendizaje y la producción de cultura, es decir la cultura produce aprendizaje y al mismo tiempo el aprendizaje produce cultura, por tanto, aprender por medio de la práctica envuelve aprender a hacer lo que ya se sabía y lo que no simultáneamente.

Los saberes y prácticas que se tejen en este contexto no se identifican con los valores de la “cultura erudita" legitimada y reproducida institucionalmente en la escuela (BOURDIEU, 1997). Por el contrario, envuelven el acervo de conocimientos y experiencias, que persisten en la memoria colectiva y popular de las gentes de la región validas e indispensables en el quehacer cotidiano de los niños, jóvenes y adultos que viven de ella y por ella.

Por consiguiente, los aprendizajes y enseñanzas que emergen en el contexto de la plaza se oponen a los valores de la cuestionable "cultura universal", ya que responden a las condiciones y necesidades inmediatas de una población heterogénea de tradición empírica, por tanto, esta contradicción no los desprovee de su relevancia y valor cognitivo y práctico.

Santos (2007) sostiene que, el conocimiento en sus múltiples formas no se encuentra distribuido equitativamente en la sociedad, ya que existe un reconocimiento privilegiado sobre el conocimiento científico occidental que le otorga una validez epistemológica y sociológica que anula otras formas de conocimiento. 
A pesar de que muchos conocimientos populares han sido reconocidos institucionalmente continúan supeditados a la hegemonía del conocimiento que privilegia las desigualdades sociales, puesto que

A actual reorganização global da economia capitalista assenta, entre outras coisas, na produção continua e persistente de uma diferença epistemológica, que não reconhece a existência, em pé de igualdade, de outros saberes, e que por isso se constitui, de facto, em hierarquia epistemológica, geradora de marginalizações, silenciamentos, exclusões ou liquidações de outros conhecimentos. (SANTOS, 2007, p. 153).

De la misma manera en que existe diversidad cultural también hay diversidad epistemológica, puesto que existen múltiples formas de "ser y estar en el mundo", que no se limitan a la percepción universalista de la ciencia moderna ni a la lógica homogeneizadora del neoliberalismo.

En ese sentido, en el contexto de la Plaza, la educación estriba en la práctica de actividades cotidianas paralelas a la educación formal. El carácter educativo de la plaza parte de relativizar los grados de conocimientos o de ignorancia que poseen los comerciantes, partiendo de que no existe un grado de ignorancia ni de conocimiento absoluto.

\section{CONSIDERACIONES FINALES}

La plaza de mercado es un espacio educativo, donde se aprende haciendo, narrando, escuchando y socializando. En donde los conocimientos crean y recrean. Se encuentran en un constante ir y venir, de boca en boca, de mano en mano. Por eso, los saberes que circulan en la plaza involucran a todas las personas que la frecuentan sin importar su edad, si son vendedores o compradores Estos saberes son volátiles y cambiantes. Sus funcionalidades y sentidos dependen de las condiciones y necesidades inmediatas de una población heterogénea fuertemente relacionada con la tradición empírica como la de la plaza.

Los saberes que circulan en la plaza de mercado del sur de Tunja, se encuentran en constante movimiento, se mezclan, transforman o conservan según sus tránsitos entre compradores y vendedores, adultos y niños. Esta dinámica contribuye a que se mantengan vigentes y vivos, a pesar de las transformaciones asumidas por la ciudad cada vez más sumergida en ritmos y rutinas que limitan y dificultan la sociabilidad, la interacción cara a cara y el contacto con los alimentos en su forma más natural, lejos de empaques, colorantes y conservantes. 


\section{REFERENCIAS}

ARCHELA, R.; GRATÃO, L.; TROSTDORF, M. O lugar dos mapas mentais na representação do lugar. Revista Geografia. Londrina, v. 13, n. 1, p. 127-141, enero/junio. 2004. Disponible en: <http://www.uel.br/revistas/geografia/ v13n1eletronica/7.pdf>.

AUGÉ, Marc. Los no lugares espacios del anonimato una antropología de la Sobre modernidad. Barcelona: Gedisa, 1992.

BARBERO, Martin. Prácticas de comunicaciónen la cultura popular:mercados, plazas, cementeriosy espacios de ocio. In: SIMPSON, M. Comunicación alternativa y cambio social. México: Editora Premia, 1986.

BERGER, P.; BERGER, B. socialização como ser um membro da sociedade. In: FORACCI, Marialice M. \& SOUZA MARTINS, José (orgs.). Sociologia e sociedade: leituras de introdução à sociologia. Rio de Janeiro: Livros Técnicos e Científicos, 1977.

BOURDIEU, Pierre. Capital cultural, escuela y espacio social. Madrid: Siglo XXI, 1997. Razones prácticas: Sobre la teoría de la acción. Barcelona: Anagrama, 1997.

CERTEAU, Michel de. La invención de lo cotidiano: 1. Un lugar común. México: Universidad Iberoamericana. 2000.

DE VARGAS, S M. Estratégias não escolares de ensino-aprendizagem e formação de professores da EJA. In: M. C. C B. FANTINATO (org.) Etnomatemática: novos desafios teóricos e pedagógicos. Niterói: Editora da UFF, 2009, p.193201.

FREIRE, Paulo. Educação e mudança. Rio de Janeiro: Paz e Terra. 2014

INGOLD, T. Pare, olhe, escute! Visão, audição e movimento humano. Ponto Urbe. Revista do núcleo de antropologia urbana da USP. n. 3, $2^{\circ}$ p. $3-53$ jul./dez. 2008. Disponible en http://pontourbe.revues.org/1925 . Acceso en 30 de septiembre de 2016.

LAVE, Jean Aprendizado como/na prática. Horizontes Antropológicos, Porto Alegre, ano 21, n. 44, p. 37-47, jul./dez. 2015 http://www.scielo.br/pdf/ha/v21n44/0104-7183-ha-21-44-0037.pdf

MATTA, Roberto da. Carnavais, malandros e heróis: para uma sociologia do dilema brasileiro. Rio de Janeiro: Zahar, 1983.

MAUSS, Marcel. Ensaio sobre a dádiva. In: MAUSS, Marcel. Sociologia e Antropologia, São Paulo: Editora da Universidade de São Paulo, 1974.

Ensayo sobre el don. In: MAUSS, Marcel. Sociología y antropología. Madrid: Tecnos S. A. 1979.

OIT. Programa Internacional para la Erradicación del Trabajo Infantil (IPEC). Disponible en <http://www.ilo. org/ipec/facts/lang--es/index.htm>. Acceso en julio 12 de 2017.

SANTOS, Boaventura de Sousa. Para além do pensamento abissal: das linhas globais a uma ecologia dos saberes. In: SANTOS, B.S.; MENESES, M.P. (Orgs). Epistemologias do Sul. São Paulo: Cortez, 2007. 


\section{RESUMEN}

Las plazas de mercado son recintos de ventas de diversos productos que, a diferencia de los supermercados y centros comerciales, son informales e itinerantes, además suscitan encuentros, intercambios, socialización, etc. por tanto, es relevante explorar los múltiples saberes y prácticas que coexisten en estos lugares. En este sentido, el presente artículo discute cómo circulan algunos saberes en la plaza de mercado del sur de Tunja (Colombia), a partir de un trabajo de campo etnográfico, que evidenció que este contexto se encuentra cargado de símbolos, signos, representaciones y subjetividades cuya relevancia va más allá de lo económico, pues se oponen a las lógicas de la globalización y su funcionalidad se da de forma alterna a los conocimientos legitimados por la escuela.

Palabras clave: Lugar antropológico, transmisión saberes, espacio socioeducativo.

\section{RESUMO}

As feiras livres são lugares de vendas de diversas mercadorias que, diferentemente dos supermercados e centros comerciais, são informais e itinerantes. Além de suscitarem encontros, intercâmbios, socialização, etc. Por isso, é relevante explorar os diversos saberes y práticas que coexistem nestes lugares. Nesta ordem, este artigo discute como circulam alguns saberes na feira do sul de Tunja (Colômbia), partindo de um trabalho de campo etnográfico que evidenciou que este contexto está carregado de símbolos, signos, representações e subjetividades cuja relevância vai para além do esfera econômica, pois se opõe às lógicas da globalização e sua funcionalidade é dada para além dos conhecimentos legitimados pela escola.

Palavras-chave: Lugar antropológico, transmissão de saberes, espaço socioeducativo.

\section{ABSTRACT}

Unlike the supermarkets and malls, the market places are enclosures where a big diversity of products are sold. Furthermore, these places are informal and itinerant; where meetings, exchanges and socializations are aroused. Thus, it is outstanding to explore multiple knowledge and practices that coexist in these places. In this regard, this article discusses how some knowledge go round the market place in the south of Tunja (Colombia), based on an ethnographic fieldwork which evinced that this context has lots of symbols, sings, representations and subjectivities whose relevance goes beyond the economic, since they put up resistance the logic of globalization and its usefulness is given alternately to the knowledge given by the academy.

Keywords: Anthropological place, transmission of knowledge, socio-educational space 